\title{
USUARIOS, CLIENTES Y CONSUMIDORES DIGITALES: CONSIDERACIONES PARA SU ABORDAJE DESDE EL MARKETING Y LA COMUNICACIÓN CORPORATIVA
}

\author{
Dr. (c) Diego Apolo Buenaño ${ }^{1}$ \\ María Victoria Altamirano Barriga \\ Verónica Estefanía Vásconez Cadena \\ María Isabel Cevallos Darquea, \\ Universidad de las Américas, Quito Ecuador \\ diego.apolo@udla.edu.ec
}

Material original autorizado para su primera publicación en la revista académica REDMARKA. Revista Digital de Marketing Aplicado.

https://doi.org/10.17979/redma.2015.01.014.4879

Recibido: 20 Abril 2015

Aceptado 5 Junio 2015

\section{Resumen}

En la actualidad, gracias a las nuevas tecnologías, la accesibilidad y el uso frecuente de las redes sociales por parte de los clientes y consumidores, las

\footnotetext{
${ }^{1}$ Ponente invitado en congresos de reconocido prestigio internacional. Ha publicado libros y artículos en revistas indexadas, además de realizar investigaciones, trabaja como docente de la carrera de Comunicación Corporativa en la Facultad de Comunicación y Artes Visuales de la Universidad de las Américas, Quito Ecuador. Doctorando en Comunicación por la Universidad Nacional de la Plata/Argentina y Dr. (c) en Ciencias de la Educación por esta misma universidad. Magister en Comunicación Estratégica Pontificia Universidad Católica de Chile, además de tener 7 años de experiencia en consultorías nacionales e internacionales.
} 
empresas se han visto en la necesidad de generar estrategias e implementar planes que permitan la gestión de su identidad digital. El consumidor se ha convertido en un mensajero de las empresas debido a los contenidos que crea en la web sobre ellas, convirtiéndose en una pieza clave en los procesos de marketing y comunicación de éstas. Además, se evidencia la relevancia que tienen los colaboradores de la empresa en la planificación de estrategias, pues son voceros permanentes de las actividades que se llevan a cabo, lo cual contribuye a fortalecer categorías como: imagen y reputación corporativas, sin dejar de lado que desde el marketing se han evidenciado casos, los que se mencionan en el desarrollo del texto, que han contribuido al logro de objetivos gracias a la compresión de la importancia de crear centros de contacto digital o social media contact center con gran éxito.

Palabras clave: Usuarios; Clientes; Consumidores; Marketing; Comunicación corporativa

\begin{abstract}
Today, due to new technologies, accessibility and frequent use of social networks by customers and consumers, companies have seen the need to develop strategies and implement plans that allow managing your digital identity. The consumer has become a messenger of companies due to the content you create on the web about them, becoming a key player in the process of marketing and communication of these. Furthermore, the relevance to consider in planning strategies to company employees is evident; because they are permanent spokesmen activities carried out, which helps strengthen categories such as corporate image and reputation, without neglecting since marketing have been evidenced cases mentioned in this article, the same who contributed to the achievement of objectives through to understand the importance of creating digital media centers or social contact center with great success.
\end{abstract}

Key words: Users; Customers; Consumers; Marketing; Corporate communication. 


\section{Introducción}

Recurriendo a los aportes de Felipe Herrera (2012), la tecnología desafía la astucia de las personas al utilizar este medio, pues los usuarios digitales son ahora los que poseen diferentes roles dentro del espacio digital. Por medio de la caracterización de los consumidores, se tratará de definir las tendencias que existen en la web, qué personas son las que lo utilizan y cuáles son los servicios tecnológicos digitales más empleados.

Se recurrió a la indagación desde diferentes autores, quienes contribuyen con pautas para tratar de abordar las situaciones que ocurren en el cotidiano digital de las instituciones.

Según Ana Bernal (2011) las redes sociales han tenido un fuerte impacto en los medios de comunicación y en la vida de sus usuarios. Esto ha conllevado un proceso rápido de adaptación y cambios a las diferentes plataformas digitales que generan nuevos espacios de interacción e intercambio de usuarios desde distintos lugares del mundo, siendo ahora los auténticos protagonistas de la red. Al pasar del tiempo, el consumo de internet se ha incrementado a gran escala en comparación a la televisión, la radio y superando de gran manera a la prensa. Uno de los principales generadores de tráfico hacia otros espacios y al consumo masivo son las redes sociales porque no son solo utilizadas por adultos, sino también por niños y adolescentes, considerados en el contexto como nativos digitales. Este medio de comunicación ha atraído a diferentes compañías que desean potenciar su marca y relacionarse directamente con los usuarios. En este contexto, muchas empresas han logrado crear una imagen amigable $y$ transparente, mientras otras han sucumbido a la moda sin percatarse que tener 
una presencial digital implica inversión de recursos económicos y de personal capacitado para gestionar esta identidad digital.

Se propone brindar una reflexión para alentar la gestión de redes sociales con fines empresariales. En este esfuerzo se ha cuestionado el impacto que generarán las mismas en la comunicación corporativa y el marketing, generando percepciones e imágenes positivas para el cliente y el consumidor, recalcando que, para ello, es necesario desarrollar una planificación previa que contenga nuevas habilidades, actitudes y sensibilidades que permitan abarcar el modelo de comunicación multidireccional que se requiere.

\section{Redes sociales: entre el marketing y la comunicación corporativa}

El ser humano es un ser social y, al vivir en sociedad, atraviesa procesos de interacción e influencia. Desde el comienzo de la historia, las personas han recurrido a diversas formas para comunicarse; sin embargo, a finales del siglo XX e inicios del XXI, se ha marcado un salto vertiginoso de inmediatez gracias a los avances tecnológicos y comunicacionales que han eliminado las barreras de tiempo y espacio, creando también nuevas tendencias y hábitos, como lo son el uso de las redes sociales.

El nacimiento de internet y el posterior aparecimiento de las redes sociales han revolucionado las maneras de relacionarse. La comunicación ha tomado uno de los lugares primordiales a ser tratados dentro de las empresas que buscan satisfacer y descubrir las necesidades de sus clientes y consumidores. De esto sobresale la necesidad imperiosa de que los actuales y futuros profesionales de marketing, publicidad y comunicación se percaten y tomen conciencia acerca del abanico de oportunidades que les puede brindar el utilizar estas nuevas herramientas digitales de modo estratégico; es decir, frenar el uso indiscriminado o por moda y direccionarlo hacia un aporte al cumplimiento de objetivos concretos.

En la actualidad, es fundamental mirar las nuevas interacciones y relaciones que se generan entre el uso de redes sociales y los usuarios, analizar su efectividad y 
definir cómo estos nuevos roles han cambiado para dar respuesta a las nuevas formas de adquisición de productos y servicios. María Saguier (2001) señala que llevamos una vida material y una vida virtual y, que en muchos casos, éstas son casi indistinguibles, pues la red cada vez es un reflejo de la vida material.

Para Juan Merodio (2010), las redes sociales son nuevos canales y herramientas de comunicación que unen a las personas a través de la web. La manera de comunicarse de la gente ha ido cambiando con el tiempo debido a las recientes tecnologías creadas. Ha sido tan grande la evolución que hoy en día existe una gama de redes sociales clasificadas según su uso y público objetivo.

Desde la perspectiva del marketing, para vender un producto o servicio es necesario tener en cuenta las cuatro P's: precio, promoción, plaza y producto. Sin embargo, ahora estas P's se han convertido en C's para la gestión de identidad digital: "contenido, contexto, conexión y comunidad" (Merodio, 2010:7). Esto se debe a que las personas crean contenidos al interactuar en la web en un sitio específico, llamado contexto, lo que lleva a generar conexiones o lazos con otros usuarios, creando una comunidad. Por ello, desarrollar estrategias digitales basadas en redes sociales son útiles y de bajo costo para llegar a los públicos objetivos de las organizaciones.

Continuando con Merodio (2010:21) el enfoque para cualquier iniciativa digital debe estar ligada a un "plan estratégico de redes sociales, el que debe ir alineado al plan estratégico global de la empresa". No sirve de nada generar estrategias al aire sin una perspectiva integral que permita en sí mismas fortalecer la comunicación digital y experiencial de la marca. Es aconsejable entonces comprender que para diseñar un plan estratégico de redes sociales se debe tener en cuenta estas cinco pautas: 


\title{
Pautas a tomar en cuenta para un plan estratégico en redes sociales
}

\author{
Es necesario que las redes sociales sean manejadas como una parte más \\ del todo, es decir, no deben ser una acción aislada a las diferentes
}

estrategias usadas en la empresa.

Se debe crear "ruido 2.0 ", que es generar más canales en la web por donde

se pueda difundir la información organizacional.

Se puede reutilizar el contenido, adaptándolo a los distintos formatos que

ofrece la tecnología, como por ejemplo, fotos, videos, podcasts, etc.

Es importante generar interés en los clientes a través de frases llamativas.

Esto hará que lean el contenido de la empresa y se interesen por ella.

Es fundamental observar el comportamiento de la competencia que ha

tenido más experiencia en las redes sociales. Esto es básico para aprender

y emular algunas de sus acciones que resulten efectivas para la compañía.

Figura 1. Elaboración propia, adaptación a partir de Merodio, 2010.

Raquel Ayestarán (2012:259) afirma que un "plan de redes sociales debe ir alineado al plan estratégico de marketing", reconociendo su importancia hacia la rentabilidad y retorno de inversión que se realice. Lo más importante de éste es su correcta planificación y estructuración desde los objetivos porque sin ellos no se tiene un rumbo definido. La autora menciona que no solamente se debe pensar en tener presencia en redes sociales y monitorearlas, sino también conocer por qué y para qué se las está integrando en la institución, como lo menciona Diego Apolo Buenaño (2014:37), "no se trata de invertir grandes cantidades de dinero en la gestión de identidad digital, se trata de conocer en realidad qué perseguimos y tener en claro qué responsabilidades asumimos al momento de abrir perfiles de instituciones en redes sociales".

REDMARKA UIMA-Universidad de A Coruña - CIECID

Año VIII, Número 14, (2015), v I pp. 3-19

http://www.redmarka.net/ ISSN 1852-2300 
Lilian San Martín y Sergio Mujica (2010:1) exponen ideas de Linton Freeman (2004), en las que afirman que las redes sociales reúnen a las personas con diferentes clases de afinidad para intercambiar información, tomar decisiones, ejercer influencias, etc. Los autores también aseveran que este tipo de comunicación permite a diferentes sujetos y grupos generar procesos de interacción social dentro de una misma web. Entre ellos también se puede incluir al gobierno, grupos de apoyo, consumidores, entretenimiento y educación, generando aproximaciones hacia nuevos modelos de comunicación que sobrepasan la unidireccional o la bidireccionalidad, es decir, se trasforman en modelos multidireccionales y multidimensionales.

Según Godoy (2009), la manera de consumo dentro de redes sociales es diferente a otras. Hay que tener en cuenta que las personas que visitan este tipo de páginas normalmente llegan ahí por su lista de contactos. Más allá de solo consumir, generan contenido para más consumidores, donde expresan sus propias opiniones, replican o apoyan opiniones de otros. Las marcas se ven atraídas por este tipo de espacios porque tienen un alto número de visitas por parte de diferentes usuarios. Éstas luchan por captar su atención y lograr un alcance orgánico; es decir, atraer a clientes por recomendación de terceros y no por anuncios pagados.

Castelló Martínez (2010:51), citando información desde Zed Digital y Nielsen Online, comenta que los consumidores son los principales promotores de las marcas, debido a su nivel de frecuencia y uso en las redes sociales. Ellos tienen el poder de potenciar o desprestigiar a una empresa en cuestión de segundos y a nivel internacional. En una encuesta realizada por las organizaciones anteriormente mencionadas, se descubrió que la fuente más confiable para los clientes es la recomendación y opiniones de otras personas que han experimentado con el producto o servicio. Este tipo de interacción entre cibernautas puede ser llamada marketing viral. 
Según Silvera Bello (2008:56), el marketing viral es una iniciativa realizada por una empresa para incentivar a los consumidores a que sean los emisores de sus mensajes. De esta manera, el cliente o consumidor se convierte en una pieza clave dentro de las estrategias de marketing. Por otro lado, desde la perspectiva de la comunicación corporativa, se vinculan las siguientes categorías: imagen, identidad y reputación (Capriotti, 2009). Éstas contribuyen a establecer procesos de investigación para la toma de decisiones y se deben construir desde la filosofía corporativay la interacción con sus públicos objetivos.

\section{Relación entre marketing viral y comunicación corporativa}

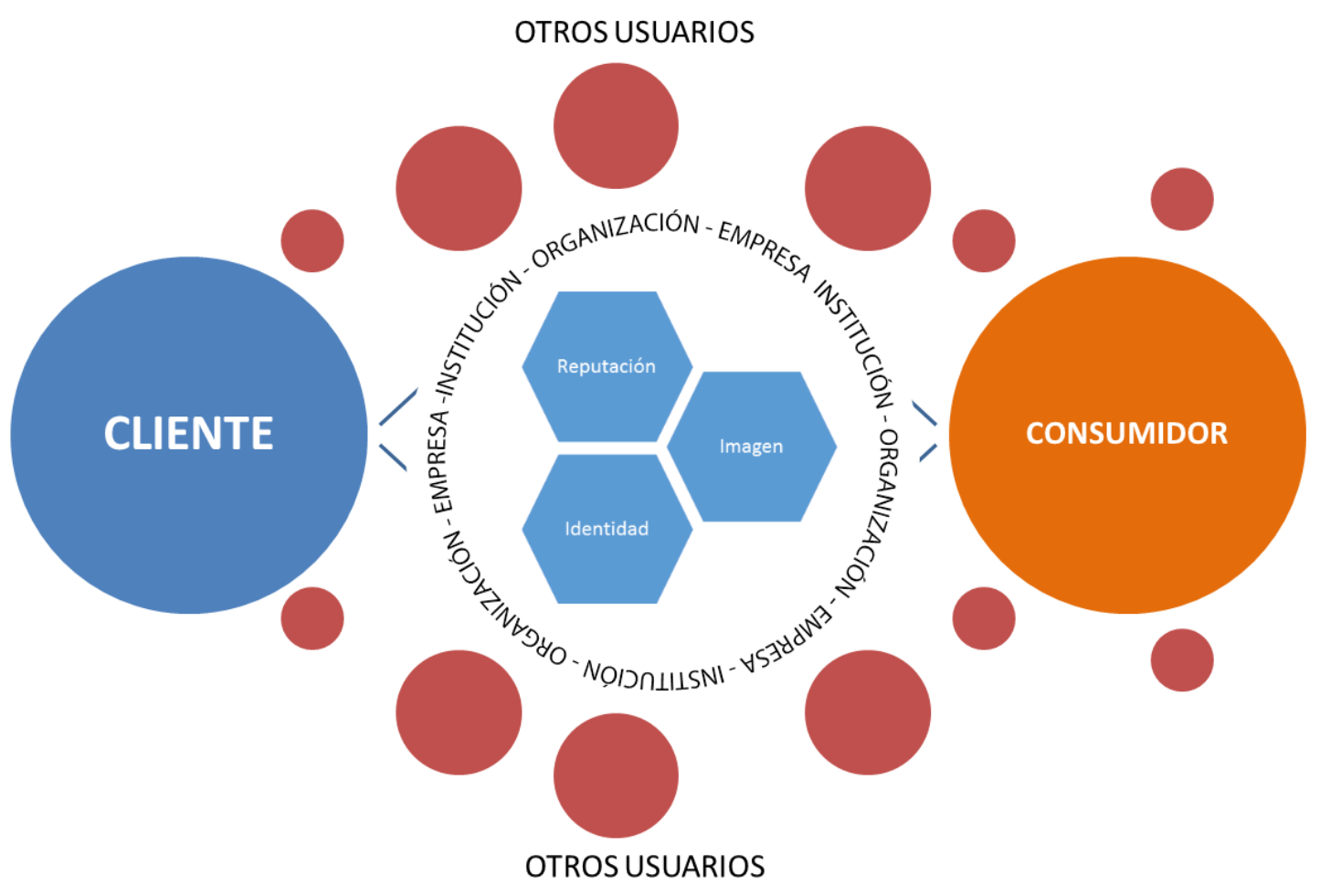

Figura 2. Adaptación propia a partir de Silvera Bello, 2008 y Capriotti, 2009.

Según Castelló Martínez (2010), la web 2.0 ha modificado la forma de consumo, por lo que las organizaciones deben estar atentas a los cambios tecnológicos para adaptarse a las necesidades de sus públicos objetivos y a sus nuevos hábitos de consumo. Actualmente, se ha modificado la forma de comunicar de las empresas 
porque ahora existe una retroalimentación desde las experiencias por parte del consumidor a gran escala, que sale del control de estas primeras. Por ello, es importante que las empresas indaguen sobre qué quieren, piensan y dicen los diferentes públicos consumidores y no sobre ellas mismas. De esta forma, se pueden identificar y mejorar productos y servicios. Gracias al internet, esto es mucho más sencillo de monitorear y, además, se puede conocer qué dicen sobre la empresa los clientes y consumidores, permitiendo tomar decisiones.

Muchas de las redes sociales ofrecen espacios publicitarios. Esto no quiere decir que, simplemente por ocuparlos, se llegue a generar retorno o un llamado a la acción. Es necesario que las instituciones, ya sean privadas, públicas o del tercer sector planifiquen el uso correcto de redes sociales para no mal gastar recursos económicos y personales.

Otro medio por el cual se puede aprovechar para gestionar estrategias digitales son espacios como: foros, fan pages, wikis, páginas de aterrizaje, blog, etc. Todas estas son utilizadas por los usuarios para compartir intereses, pero las empresas también las pueden utilizar para compartir información y estrechar lazos con otros usuarios.

\section{Redes sociales y tendencias actuales}

Las redes sociales han sido identificadas como un lugar de interacción digital al que tienen acceso millones de personas en el mundo. Se las han clasificado como un medio informal de comunicación potencializado gracias a los nuevos dispositivos móviles como teléfonos inteligentes, tablet, computadoras personales, entre otros. Estos dispositivos han permitido el intercambio en tiempo real de mensajes desde cualquier lugar del mundo y han brindado la facilidad para el manejo de redes sociales, convirtiéndolas en la actualidad en un hábito de consumo permanente. Es importante reconocer que dentro de estas plataformas los usuarios son quienes comparten y alimentan los espacios. Con el pasar del tiempo, las redes sociales han sido aprovechadas desde todos los ámbitos: 
profesionales, empresariales, políticos, entre otros; donde primordialmente prima la promoción, libre opinión y, sobre todo, la retroalimentación, que ha fortalecido de una manera indudable el poder de los clientes y consumidores. En este sentido, Álvaro Gómez y Carlos Otero (2013:23), mencionan que el hecho de poder publicar y difundir al mundo cualquier mensaje, es el ejemplo más concluyente de libertad y conexión que supone el internet, además de que ha puesto en igualdad de oportunidades "a las grandes empresas y a los ciudadanos de a pie".

Actualmente, la proliferación de distintas plataformas de redes sociales con usos y aplicaciones diferentes ha generado en los usuarios la necesidad de ir abriendo cuentas en éstas. Por ello, dichas plataformas han desarrollado nuevas funciones que permiten vincularse entre ellas con los perfiles de los usuarios.

Dentro de las instituciones debe existir un debate y reconocer si la necesidad de tener presencia en la web contribuye al logro de los objetivos, además de realizarse ciertas preguntas como: ¿Tenemos claro cuál es el objetivo? ¿Estamos preparados para asumir estas responsabilidades? ¿La persona que maneja nuestra identidad digital está preparada? (Apolo, 2014:37).

Entre las redes sociales que mantienen tendencia se puede mencionar a:

\begin{tabular}{|c|c|c|c|}
\hline Linkedln & Twitter & Facebook & Googlet \\
\hline $\begin{array}{l}\text { Fue fundada por Reid } \\
\text { Hoffman y lanzada al } \\
\text { mercado en } 2003 \text {. Está } \\
\text { enfocada esencialmente } \\
\text { en el networking entre } \\
\text { profesionales y permite } \\
\text { publicar a modo de hoja } \\
\text { de vida, el perfil } \\
\text { académico y la } \\
\text { experiencia profesional } \\
\text { de cada usuario. Entre } \\
\text { otras funciones tiene: }\end{array}$ & $\begin{array}{l}\text { Fundada por Jack } \\
\text { Dorsey y lanzada al } \\
\text { mercado en el } 2006 \text {. En } \\
\text { esta red social los } \\
\text { usuarios pueden publicar } \\
\text { mensajes cortos, } \\
\text { denominados tweets, } \\
\text { con una extensión } \\
\text { máxima de } 140 \\
\text { caracteres para } \\
\text { comentar cualquier } \\
\text { evento, opinión o estado }\end{array}$ & $\begin{array}{l}\text { Es considerada la red } \\
\text { social más popular de } \\
\text { todas. Fue creada por } \\
\text { Mark Zuckerberg y } \\
\text { lanzada al mercado en el } \\
2006 . \text { Permite definir y } \\
\text { publicar un perfil de } \\
\text { usuario que contiene } \\
\text { datos } \\
\text { sociodemográficos, } \\
\text { estudios, intereses, y } \\
\text { aficiones. Asimismo, se }\end{array}$ & $\begin{array}{l}\text { Fue lanzado en el } 2011 \\
\text { ante el increíble } \\
\text { crecimiento de } \\
\text { Facebook. Incluye varios } \\
\text { servicios de red social, } \\
\text { cloud, computting, chat y } \\
\text { videoconferencia. Se } \\
\text { distingue entre otras } \\
\text { aplicaciones por su } \\
\text { preocupación por } \\
\text { salvaguardar la } \\
\text { privacidad de los }\end{array}$ \\
\hline
\end{tabular}




\begin{tabular}{|c|c|c|c|}
\hline $\begin{array}{l}\text { gestión de lista de } \\
\text { contactos, sistema de } \\
\text { mensajería interna, } \\
\text { solicitud de } \\
\text { recomendaciones, } \\
\text { buscador de usuarios } \\
\text { registrados, participación } \\
\text { en grupos de debate, } \\
\text { herramientas para } \\
\text { facilitar selección de } \\
\text { candidatos, inserción de } \\
\text { mensajes publicitarios. }\end{array}$ & $\begin{array}{l}\text { de ánimo que se desee. } \\
\text { Además, se pueden } \\
\text { incluir "\#hashtags" para } \\
\text { identificar a los tweets } \\
\text { dentro de un tema } \\
\text { general. Los usuarios } \\
\text { pueden subscribirse a } \\
\text { las cuentas de otras } \\
\text { personas que quieran } \\
\text { como sus "seguidores" y } \\
\text { así poder leer todo lo } \\
\text { que se publica. Existe } \\
\text { también la opción de } \\
\text { configurar la privacidad } \\
\text { de la cuenta para que } \\
\text { solamente tengan } \\
\text { acceso a la información } \\
\text { ciertas personas. }\end{array}$ & $\begin{array}{l}\text { pueden publicar estados, } \\
\text { notas, fotos, videos, y } \\
\text { compartirlo con otros } \\
\text { usuarios en su "muro". } \\
\text { Además, se puede } \\
\text { acceder a una gran } \\
\text { variedad de aplicaciones } \\
\text { y juegos que son } \\
\text { desarrollados por } \\
\text { empresas y por } \\
\text { programadores externos } \\
\text { de Google. Por otro lado, } \\
\text { esta red social no solo } \\
\text { se enfoca a jóvenes } \\
\text { universitarios, sino a } \\
\text { todos los segmentos de } \\
\text { la población, también a } \\
\text { empresas y a otro tipo } \\
\text { de organizaciones que } \\
\text { pueden tener sus } \\
\text { páginas o fanpages. Sus } \\
\text { ingresos se centran } \\
\text { fundamentalmente en la } \\
\text { inserción de anuncios } \\
\text { publicitarios y comercio } \\
\text { electrónico. }\end{array}$ & $\begin{array}{l}\text { usuarios, permitiendo } \\
\text { definir círculos de } \\
\text { contactos a los que solo } \\
\text { llega el tipo de } \\
\text { información que el } \\
\text { cliente haya configurado. }\end{array}$ \\
\hline
\end{tabular}

Figura 3. Adaptación propia a partir de Gómez y Otero, 2013.

\section{Un diálogo necesario}

La revolución digital, sucedida principalmente desde 1990, ha provocado un singular fenómeno que Alvin Toffler (1970) denominaba information overloadd, traducido desde varios aportes al castellano como infoxicación o sobrecarga de información. Esto se refiere al hecho de que la disponibilidad inmediata de tecnología y la excesiva oferta de los medios de difusión han causado que el usuario se acostumbre a éstos y que sea mucho más difícil para las empresas captar su atención debido al exceso de información verdadera y falsa. No es 
extraño ver a personas utilizando varios medios al mismo momento; es decir, mientras escuchan la radio, tienen la televisión encendida, leen una revista, sin descuidar lo que acontece en sus perfiles o de sus contactos en redes sociales. Inclusive Gómez y Otero (2013:63) dicen que "estudios sobre audiencia de los medios de comunicación apuntan a una caída del consumo medio semanal de televisión a favor del tiempo dedicado a internet sobre todo en los segmentos más jóvenes de la población".

Es relevante tomar en cuenta estos datos para planificar un modelo de negocio enfocado en los clientes y consumidores. Las organizaciones ya no pueden darse el lujo de satisfacer una sola necesidad. Ahora deben indagar en cada detalle para encontrar un diferenciador para su público objetivo, pues como lo mencionan Gómez y Otero (2013), el mercado está sobre poblado de productos; el comprador se encuentra mucho más informado que antes; el cliente es exigente, ya no se fija únicamente en calidad o precio, sino también en el funcionamiento responsable de la institución, y además, puede estar respaldado por una comunidad enorme de usuarios con quienes comparte sus experiencias, marcando así una referencia que podría ser una ventaja o desventaja para la institución.

Juan Carlos Jiménez (2011: 24) menciona que "desde el punto de vista de imagen corres más riesgo dejando de participar en las redes sociales que participando". E tener presencia en estos medios no sirve solamente para generar mensajes, sino para conocer también qué dicen sobre la empresa. En este caso Apolo Buenaño (2014:37) menciona "hacer algo en internet es barato, no hacer nada puede costar muy caro". A través de ellas, se tiene una gran base de datos donde se puede conocer los problemas, inquietudes y preferencias de las personas; identificar oportunidades de negocio; generar fidelidad, entre otras. Es así como las empresas se tienen que centrar en fortalecer y valorar el intercambio que se da con sus usuarios más allá de lo económico, con el fin de que la información sea utilizada para satisfacer necesidades y crear nuevas emociones que acompañen a la marca. 


\section{Los colaboradores como portavoces}

Las redes sociales también pueden ser potencializadas al interior de la organización para traer beneficios tanto internos como externos (Jiménez, 2011). A través de este espacio de interacción virtual, el equipo de trabajo puede ser involucrado para ser voceros y representantes de la misma, atendiendo las inquietudes y demandas de los clientes y consumidores en la comunidad virtual. El autor toma como ejemplo el caso de Best Buy, empresa que ha preparado a sus colaboradores para que participen en este medio y así potencializar el servicio de la organización. Actualmente, tiene a más de 2300 empleados respondiendo y asesorando a clientes a través de su cuenta en Twitter, pues es un medio con el que los usuarios están familiarizados, confían, pueden ser rápidos, directos y menos formales para presentar sus inquietudes.

Además, es una buena manera para que el equipo de trabajo se sienta integrado con la cultura corporativa, pues tienen que estar informados en su totalidad de toda la información y actividades de la misma para poder responder a los tweets de los beneficiarios, los que pueden ser de toda índole. Por otro lado, si los colaboradores se sienten integrados a la cultura de la institución, apoyarán, hablarán y transmitirán información positiva en las redes sociales sobre los beneficios de ser parte de ella y así también atraerán a más talento humano.

Las organizaciones pueden aprovechar de ciertos servicios que ofrecen las redes sociales para apoyar su gestión y operaciones. Por ejemplo, existen medios sociales que pueden transferir y compartir datos y/o almacenar documentos mejor que el correo, como Dropbox y Google Drive, plataformas gratuitas que almacenan datos en la nube, lo que contribuye a que no se congestionen las redes internas.

Según Cristina Aced (2010:29), ciertas empresas han aprovechado al máximo las comunidades virtuales para realizar investigaciones de mercado permanentes y de manera gratuita aprovechando redes como Facebook, donde los usuarios brindan una extensa base datos de sus actividades y gustos de forma voluntaria. 
Finalmente, existen instituciones que han propuesto ideas en sus redes sociales para incluir a sus clientes y que ellos contribuyan a mejorar la empresa. En el 2009, la empresa Starbucks recibió de sus clientes más de cien mil ideas para fortalecer su negocio a través de su cuenta Twitter. Es importante resaltar que los consumidores estarán más incentivados a participar en su red social si es interesante y periódica, si publica promociones y/o información relevante para ellos, que tenga que ver con la actividad empresarial (Jiménez:21-25) y el tipo de consumo de dichos usuarios. Hay que tomar en cuenta el lugar de acceso de los usuarios a la web. En este caso, Bernal (2011) menciona que éstos acceden a internet principalmente desde dispositivos móviles como teléfonos inteligentes y tabletas. Para identificar esto, es importante realizar pruebas de usabilidad 0 funcionamiento de la web institucional en dispositivos.

Junto a ello, es fundamental ser coherentes entre lo que se dice y lo que se hace. Debido a la sobre-información, los usuarios de redes sociales no se dan el tiempo necesario para comprobar la legitimidad de un hecho. Si le llama la atención, lo viraliza. Así, si una empresa, por ejemplo, emite un comunicado en el que dice poseer "productos amigables con el ambiente", el usuario podría creerlo, pero corre el riesgo de que si éste llega a dudar o a comprobar que no es así dicha información, comparta la mentira a sus contactos y el rumor se esparza. Si bien es cierto, es difícil proteger a una compañía de comentarios falsos, la clave está en la agilidad de acción y el monitoreo constante del boca a boca.

\section{Conclusiones}

Las redes sociales han pasado a ser parte de la vida cotidiana de las personas y las empresas no han desaprovechado este hecho, sacando el mayor partido para mejorar varios aspectos de sus procesos. Sin embargo, una gran mayoría de altos mandos continúan dirigiendo sus empresas y a sus colaboradores sin tomar en cuenta el poder de las redes sociales como mecanismos de aumento de 
productividad y rentabilidad desde marketing. De igual manera, ignoran el impacto que tiene la comunicación corporativa y su efecto en la imagen y reputación.

En cuanto a las redes sociales más utilizadas se encuentran: Facebook, Twitter, Youtube, Linkedln, entre otras. El saber administrar correctamente estas plataformas digitales aportará enormemente a la empresa, pues se dará a conocer de una manera amigable y directa a sus clientes y consumidores, permitiéndoles compartir información sobre las actividades, productos, servicios, eventos y demás acciones que ésta realiza. Además, hay que tomar en cuenta que todo lo antes mencionado debe regirse bajo un plan estratégico de redes sociales que se soporte en la construcción de su gestión de identidad digital y que esto debe ir de la mano del plan estratégico institucional desde marketing, publicidad y/o comunicación, dependiendo de sus objetivos.

Los altos mandos en instituciones deben comprender que para llevar a un llamado a la acción del consumidor digital, el valor fundamental de todo el trabajo está en la investigación y el relacionamiento. Se debe dejar de lado, en muchos casos, la formalidad tradicional y dar paso a relaciones amigables horizontales con los cibernautas. Además, no se debe permitir que cualquier persona maneje la identidad digital de la empresa, pues cada acción de la marca llega a millones de usuarios $y$, un solo error, puede costar muy caro. Asimismo, se debe continuar discutiendo sobre la pertinencia de tener o no perfiles digitales. Sus acciones deben basarse en un plan de gestión de identidad digital para generar procesos de comunicación. Éstas deben llevar a las instituciones a desarrollar un centro de contacto digital o social media contact center que contribuya al logro de sus objetivos y no ser espacios únicamente dedicados a emitir información. 


\section{Bibliografía}

Aced, C. (2010). Redes Sociales en una semana. Barcelona: EDICIONES GESTION 2000.

Ayestarán, R. (2012). Planificación estratégica y gestión de la publicidad. Madrid: ESIC EDITORIAL.

Apolo Buenaño, D. (2014). "No todo número es un dato: el mea culpa de las instituciones en redes sociales." En Revista Dircom (104), p. 37.

Bernal, A. (2011). Redes sociales y medios de comunicación. Un reto y una oportunidad. Granada: Grupo Labcom. Universidad de Málaga para ATR Andalucía.

Capriotti, P. (2009). Branding Corporativo: Fundamentos para la gestión estratégica de la Identidad Corporativa. Santiago de Chile: Business School Universidad Mayor.

Castelló Martínez, A. (2010). Estrategias empresariales en la Web 2.0. Alicante: Editorial Club Universitario 
Freeman, L. (2004). The Development of Social Network Analysis: A Study in the Sociology of Science. Vancouver: Empirical Press.

Godoy, J. (2009). Redes sociales y comunidades. En Sanagustín, E. (2009): Del 1.0 al 2.0 Claves para entender el nuevo Marketing. Madrid: Bubok Publishing.

Gómez, A y Otero, C. (2013) Redes Sociales en la empresa. Bogotá: Ediciones de la U.

Herrera, F. (2012) Tendencias del usuario digital Chileno en 2012. Santiago de Chile: IAB Chile.

Herrera, F. (2013). Manual de orientación para participar en redes sociales. New York: Banco Interamericano de Desarrollo.

Jiménez, J. (2011). Diálogo 2 punto 0. Caracas: Cograf Comunicaciones.

Merodio, J. (2010). Marketing en Redes Sociales. Mensajes de Empresa para gente selectiva. Madrid:Bubok Publishing.

Saguier, M. (2001). "Relaciones Familiares en la Era de Internet: ¿hacia dónde?” En Revista Kairos N. 10.

San Martín, L. y Mujica, S. (2010). Redes sociales: la nueva forma de comunicación de los jóvenes. Arequipa: Latin American and Caribbean Conference for Engineering and Technology.

Schawbel, D. (2011). Aproveche las redes sociales en su promoción personal. Barcelona: Kaplan Publishing.

Silvera Bello, S. (2008). Marketing viral. Barcelona: Editorial UOC.

Toffler, A. (1970). Future shock. New York: Amereon Ltd. 